\title{
Nutritional influences on reproduction in mature male sheep and goats
}

\author{
G. B. Martin ${ }^{1,2}$ and S. W. Walkden-Brown ${ }^{1}$ \\ ${ }^{1}$ School of Agriculture, University of Westem Australia, Nedlands 6009. Australia; and ${ }^{2}$ CSIRO \\ Division of Animal Production, Private Bag. Wembley 6014, Australia
}

\begin{abstract}
Changes in the nutrition of mature rams and goat bucks lead to profound responses in testicular size and therefore the rate of production of spermatozoa. These effects are largely due to changes in the size of the seminiferous tubules and in the efficiency of spermatogenesis. With the exception of severe undernutrition, the effects on spermatogenic function are not accompanied by similar changes in endocrine function of the testes, as measured by the production of testosterone or inhibin. In rams, moderate changes in nutrition affect gonadotrophin secretion for only a few weeks, whereas testicular growth is affected for several months. In mature male goats during the non-breeding season, nutrition-induced testicular growth does not seem to be associated with a gonadotrophin response. Such observations have led us to develop the hypothesis that nutrition-driven testicular growth is at least partly independent of changes in gonadotrophin secretion. The energetic components of the diet, rather than the protein content, seem to be responsible for affecting gonadotrophin secretion in rams. The volatile fatty acids, and not glucose, are the active factors, although intracerebral insulin may also play a role. Where these substrates act and whether they are also involved in the gonadotrophin-independent pathways requires testing. In conclusion, nutritional signals exert powerful effects on the reproductive system of mature male ruminants, and the responses are partly independent of changes in gonadotrophin secretion. In the gonads, the gametogenic tissue responds rapidly to changes in nutrition, but the endocrine compartments are less affected. Variations in the expression of the nutritional responses among sexes, breeds and species probably reflect variations in the role of this environmental factor as a modulator of reproductive function.
\end{abstract}

\section{Introduction}

Nutritional influences on reproduction in farm animals were probably recognized soon after domestication. However, Clark (1934) probably provided the first experimental evidence for gonadal effects when he related the effect of 'flushing' on lambing rate in sheep to an increase in ovulation rate, a phenomenon that still intrigues reproductive physiologists. The emphasis on females was noted by Moule (1963), who reviewed the ruminant literature and was unable to find a systematic study of the effects of nutrition on semen production in male domestic animals. We are now beginning to develop an integrated view of how nutrition influences both the gametogenic and endocrine functions of the testis. The roles of nutrition in the control of puberty, and the production and fertilization of oocytes or the nurture of zygotes, from embryo to fetus to newborn, have recently been reviewed by Lindsay et al. (1993) and Foster (1994). We will focus on mature males and the endpoint will be the gametogenic and endocrine activity of the testes. Although our own studies are largely limited to Australian goats and sheep, we will integrate them with work on other breeds and environments, and we also attempt 


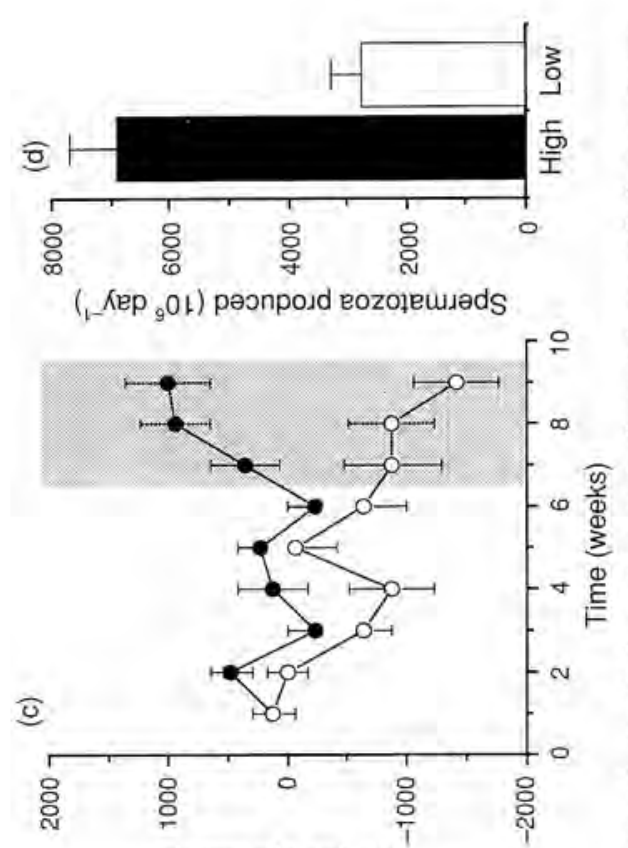

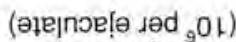

eozole

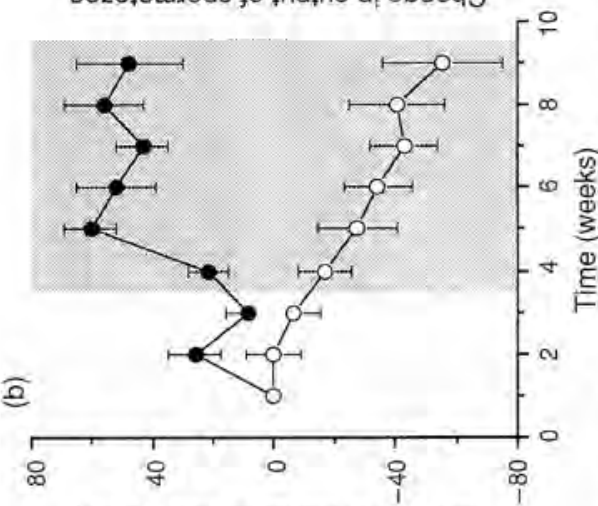

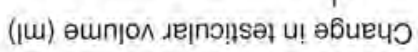
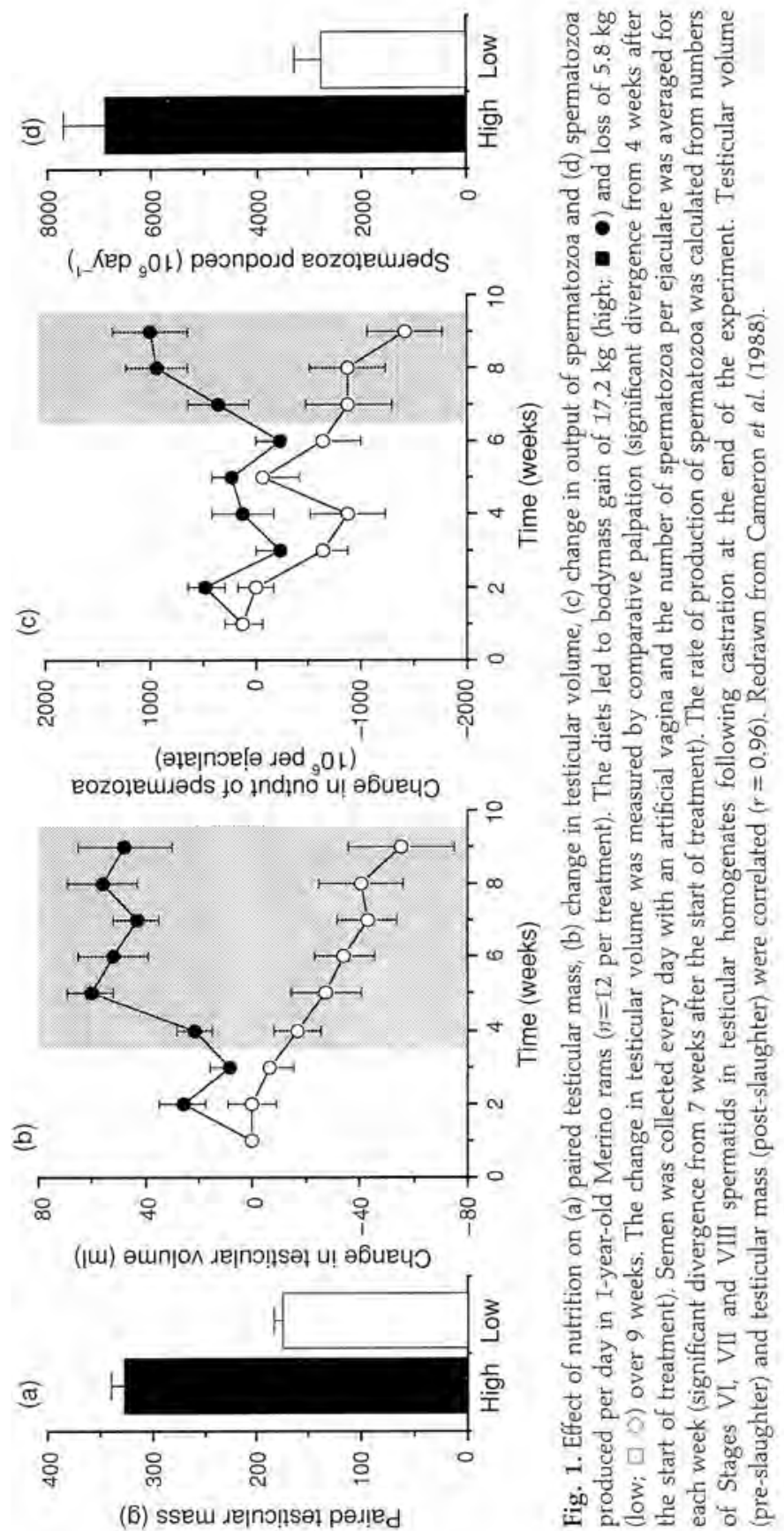
to address related issues for cattle. The discussion will be restricted to the effects of shifts in energy or protein balance of similar magnitude and duration to those that would be experienced by animals grazing natural forage, avoiding the effects of extreme nutritional deprivation, and the pathology associated with specific deficiencies and toxicities.

\section{Testicular responses to nutrition}

In Merino rams in particular, the production of spermatozoa has been shown to be very responsive to changing nutrition in a number of studies using a variety of techniques (Mori, 1959; Salamon, 1964; Setchell et al., 1965; Braden et al., 1974; Oldham et al., 1978; Alkass et al., 1982; Martin et al., 1987; Cameron et al., 1988; Murray et al., 1990). Hiroe and Tomizuka (1965) found that loss of body mass in goats was associated with reductions in the output of spermatozoa. There were some negative findings in sheep (Tilton et al. 1964), but there is now general acceptance of the strong, direct relationships between plane of nutrition, testicular mass and the number of spermatozoa available for ejaculation, for the small ruminants at least (Fig. 1).

In rams, changing nutrition alters not only the total amount of testicular tissue, but also the efficiency with which the gametes are produced by that tissue. This is evident from the fact that changes in sperm production are consistently greater than those in testicular mass. For example, Oldham et al. (1978) found that a $25 \%$ increase in testicular size led to an $81 \%$ increase in production of spermatozoa, and Cameron et al. (1988) found that an $86 \%$ increase in testicular size led to a $250 \%$ increase in production of spermatozoa. The number of ejaculated spermatozoa is not affected until 7 weeks after a change in diet (Fig. 1), suggesting that the effects on spermatogenic efficiency are exerted after the last spermatogonial division. This is similar to the effects of stimulatory photoperiod in more seasonal breeds of sheep, in which efficiency is increased by reducing the rate of degeneration of germ cells following the mitotic and meiotic divisions of the spermatogenic cycle (Hochereau-de Reviers $e t$ al., 1985). Detailed cytological analysis is needed to determine whether nutrition operates by this mechanism, and also to determine the relative roles of FSH, testosterone and $\mathrm{LH}$ in mediating these responses in the testes. The gross histology carried out to date has shown that nutrition markedly affects the diameter of the seminiferous tubules (Setchell et al., 1965), the relative proportion of the testes occupied by the seminiferous tubules and the proportion of the seminiferous tubule occupied by the seminiferous epithelium (Oldham et al., 1978).

If changes in production of spermatozoa result primarily from alterations in Sertoli cell function, it is peculiar that peripheral inhibin concentrations do not seem to be affected by diet in mature Merino rams, despite clear effects on FSH concentrations and testicular mass (Martin et al., 1994a). At this stage, we cannot explain this observation, although it does suggest that the endocrine and spermatogenic functions of the tubules are regulated differentially.

The effects of nutrition on the activity of the interstitial tissue should be reflected in rates of production of testosterone. However, in mature Merino rams, significant changes in testicular mass induced by nutritional treatments were not associated with changes in the size of the response of testosterone to LH (Ritar ef al., 1984; Martin et al, 1987; 1994a). This result appears to conflict with the effects of photoperiodic season on testicular growth and function (Lincoln and Short, 1980), as well as the detailed work of Setchell et al. (1965) on nutritional responses in Merino rams. These workers measured the total testicular production of testosterone and supported these data with observations on the number and staining intensity of the interstitial cells. Apart from the major difference in endocrine technique, this work appears to differ from our studies in the severity of dietary treatments. Setchell ef al. (1965) compared rams that were severely underfed for 3 months (body fat was reduced to less than $12 \%$ of live mass) with rams that were probably obese ( $25-49 \%$ fat). In our laboratory, we have studied the testosterone responses to exogenous LH in rams on more extreme diets (M. J. Hötzel, 1994, personal communication), and the data confirm the observations by Setchell et al. (1965). There appears to be a range of nutritional regimens within which testosterone production is not altered. However, when the loss of body and testicular mass is severe and protracted, testosterone production is reduced. The mechanisms underlying this sort of response may be similar to those underlying changes driven by photoperiod. 


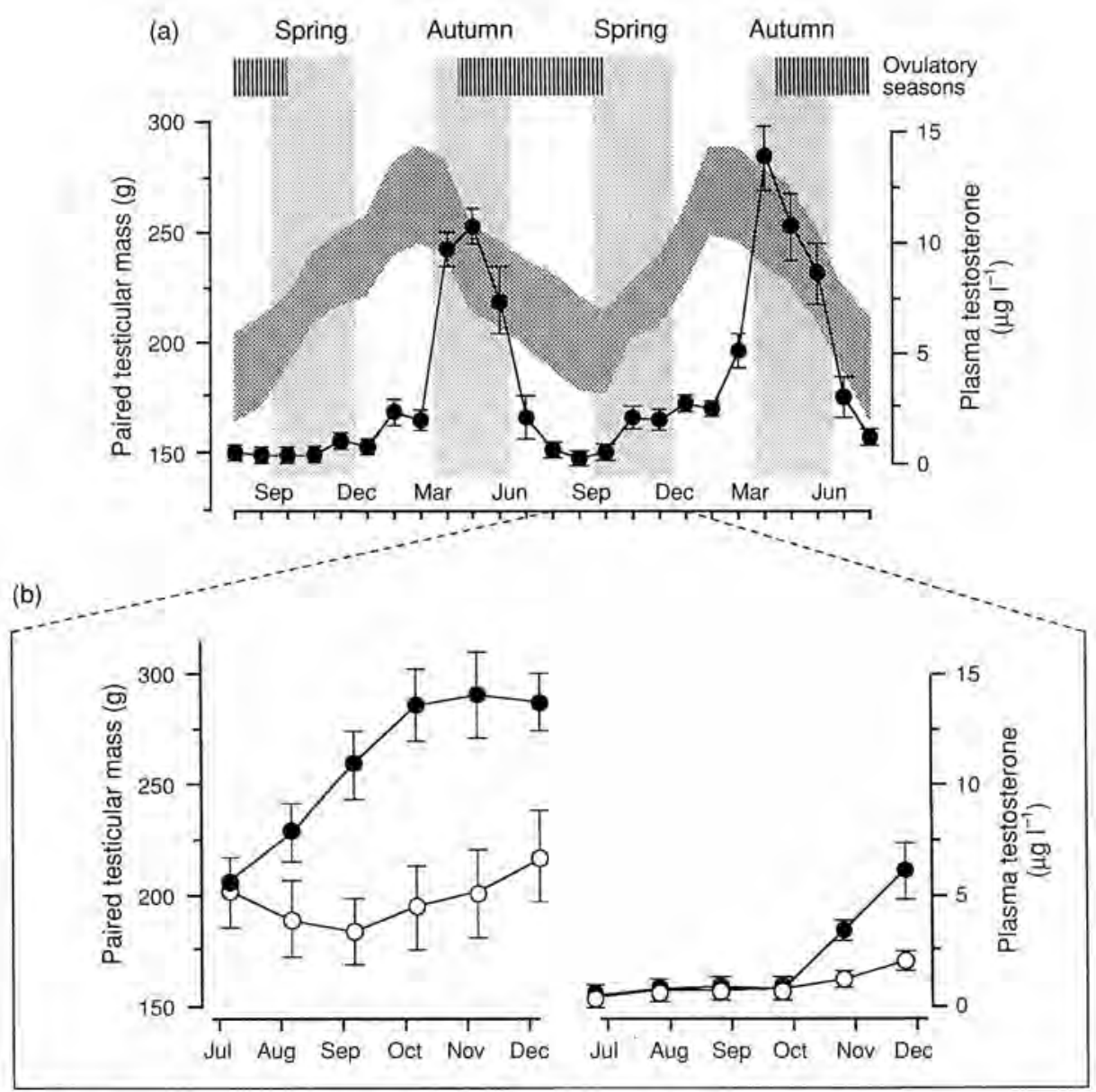

Fig. 2. (a) The seasonal cycles in testicular mass (shaded area; mean \pm SEM; $n=6$ ) and plasma concentrations of testosterone ( $)$ in Australian feral goat bucks at pasture in a subtropical climate at $29^{\circ} \mathrm{S}$ (modified after Walkden-Brown et al. 1994b). The periods of ovulatory activity in females are also indicated (Restall, 1992). (b) Testicular mass and testosterone concentrations (mean \pm SEM) during the non-breeding season in bucks fed a maintenance diet $(0 ; n=6)$ or a high plane of nutrition $(\bullet, n=6)$. Adapted from Walkden-Brown et al. (1994c).

In goat bucks, the difference in responses to nutrition between testicular compartments is even more pronounced. Large differences in testicular size induced by nutrition during the non-breeding season were not associated with any change in testosterone concentrations until about four months later (Fig. 2).

These apparently conflicting effects of nutrition on testosterone production in sheep and goats emphasize the need to address differences between species, ages and methods. In rams, the relative importance of gonadotrophin secretion and testicular responsiveness to LH in mediating the effects of nutrition on testosterone secretion need to be assessed. In breeds and species that also respond strongly to photoperiod, the contrast between the changes in testosterone production with season and the lack of testosterone response to nutritional supplements during the non-breeding season need to be considered. Few studies have been carried out to determine whether these problems reflect differences between species or between experimental methods. Future studies should include quantification of Leydig cell activity, as well as measurement of clearance rates for testosterone and inhibin, and the secretion of testosterone and inhibin (total testicular secretion and responsiveness to $\mathrm{LH}$ ). 


\section{Physiological mechanisms}

\section{Role of body mass and composition}

Much of the research on nutritional effects on reproduction has been descriptive, providing many detailed mathematical relationships between reproductive variables (for example age of puberty, ovulation rate, testicular size) and measures of body development (for example mass, rates of gain, composition). This is particularly so for puberty because, across a wide range of species, the onset of puberty is very poorly related to chronological age and very closely related to measures of body development. However, these direct relationships are complicated by several effects, including growth rate, compensatory growth, and mature body size (review: Lindsay et al., 1993). Moreover, none of these phenomena provides a very useful guide to the mechanisms involved (Schillo, 1992). The suggestion that the proportion of body fat controls the onset of puberty in humans (Frisch, 1974) raised the possibility of physiological interactions between the systems that control metabolism and reproduction. However, under close scrutiny, the relationship did not seem to hold for sheep or pigs (Lindsay et al., 1993), and was largely dismissed by Bronson and Manning (1991), who reviewed the literature and concluded that there is no evidence for a direct causal role of body fat in regulating ovulation.

For mature animals, similar conclusions can be drawn. In rams, for example, Salamon (1964) found that sperm production was affected by nutrition in the absence of any significant change in bodymass. It seems that rams can show a 'flushing' effect similar to that of ewes, in which ovulation rate can change without any change in bodymass (Clark, 1934). There is little doubt that change in bodymass is a consistent correlate of change in testicular size, but it is only consistent, not universal, and it has led to few advances in our understanding of physiological processes linking nutritional input with reproductive output. It is important to remember that gonadal output and bodymass are both merely endpoints in the response to nutrition.

\section{Role of GnRH and gonadotrophins}

Work on photoperiodic control of testicular growth in rams (Lincoln and Short, 1980) led to the hypothesis that there is a simple relationship between plane of nutrition, gonadotrophin secretion and testicular growth, based on changes in the frequency of the GnRH pulses secreted by the hypothalamus. This approach was supported by the observation that a low plane of nutrition reduced plasma $\mathrm{LH}$ concentrations in mature rams (Alkass et al., 1982). However, from the beginning, the data derived from mature Merino rams implied that changes in gonadotrophin secretion would be only part of the story. Addition of lupin grain to a maintenance diet led to an increase in LH pulse frequency within 2-3 days, but it was sustained for only a few weeks before returning to control frequencies (Ritar et al., 1984; Martin et al., 1994a). An increase in the concentration of FSH is also detected after a delay of 5-14 days, but then it too disappeared (Martin et al., 1994a). Reducing the plane of nutrition below the requirement for maintenance led to rapid decreases in LH pulse frequency, testicular size and bodymass, but FSH concentrations were not affected. Again, the LH profiles returned to normal after a few weeks, when there was no further loss of bodymass (i.e. maintenance was restored). Despite similar patterns of gonadotrophin secretion, testicular sizes continued to diverge in response to plane of nutrition (Martin et al, 1994a).

All of these gonadotrophin responses can be reproduced in short-term castrated rams subjected to the same dietary treatments, but only when they are treated with exogenous testosterone and inhibin (Martin et al., 1994b). It seems likely that the gonadotrophin responses are due to effects exerted on the hypothalamus and pituitary gland because, in rams at least, diet does not seem to affect the clearance of testosterone (Parr and Tilbrook, 1990), although the design of this experiment was not ideal and the clearance of inhibin has not been studied.

Overall, it is clear that hypothalamic pathways controlling GnRH pulse frequency in mature rams do respond to changes in nutrition. We have done many experiments over the past few years and the endocrine response to lupin supplements over the first few weeks is so consistent that it has become the basis of our attempts to understand the neuroendocrine systems that are involved in the interactions between nutrition and testicular activity. 

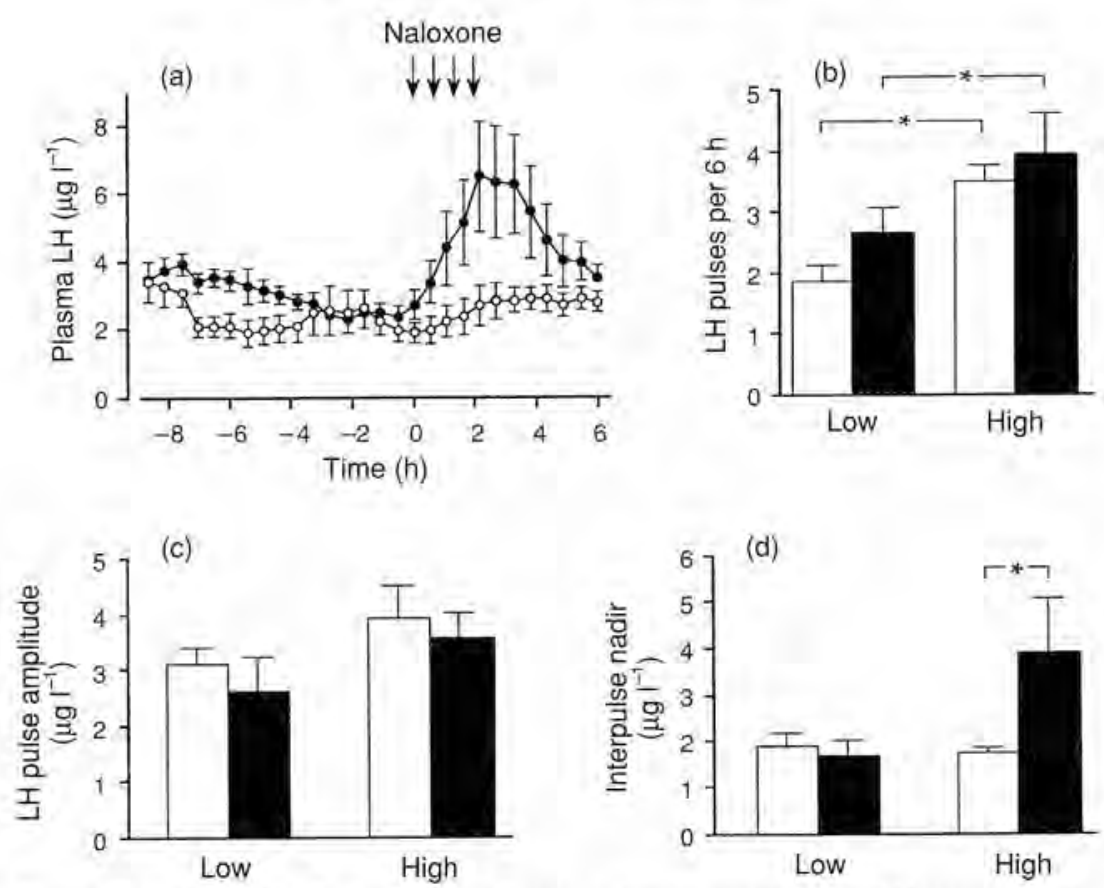

Fig. 3. The effect of inhibition of opioidergic pathways on (a) plasma LH concentrations (b) number of LH pulses in $6 \mathrm{~h} \mathrm{(c)} \mathrm{LH} \mathrm{pulse} \mathrm{amplitude} \mathrm{and} \mathrm{(d)} \mathrm{interpulse} \mathrm{nadir} \mathrm{in} \mathrm{mature}$ Merino rams that had been fed below maintenance (low) or above maintenance (high) for 6 weeks. They were injected (i.v.) with naloxone $\left(2 \mathrm{mg} \mathrm{kg}^{-1}\right.$ in the first instance, followed

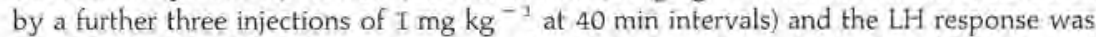
observed in blood sampled every $20 \mathrm{~min}$ for $8 \mathrm{~h}$ before ( $\square$ ) and $6 \mathrm{~h}$ after (回) the initial naloxone injection. All values are means $\pm \operatorname{sem}(n=5) .{ }^{*} P<0.05$. Mean concentrations were calculated using a moving average over nine consecutive samples ( $3 \mathrm{~h}$ ), and every second point is presented for the sake of clarity. Data from Miller et al. (1992) with permission.

In mature Cashmere bucks, the acute effects of differential nutrition have been tested only during the non-breeding season, and the rapid diversion in testicular size induced by the diets was not associated with changes in LH or FSH secretion (Walkden-Brown et al., 1994c). Animals as seasonal as these might show gonadotrophin responses to nutrition only under stimulatory photoperiod, so we clearly need to repeat this study during the breeding season.

Role of opioidergic systems. The opioidergic system of the brain is one of many that inhibits the activity of GnRH cells in sheep and it is thought to play a role in the effects of gonadal steroids and photoperiod (Schanbacher, 1985; Lincoln el al., 1987; Thiéry and Martin, 1991). We hypothesized that opioidergic inhibition would be most active in rams on low planes of nutrition, in which steroid feedback is most effective and LH pulse frequency is low. However, when Miller et al. (1992) injected naloxone into Merino rams that had been fed differentially, only the group on the high plane of nutrition showed a significant increase in $\mathrm{LH}$ secretion (Fig. 3).

In this regard, the effects of nutrition and photoperiod are similar, as naloxone is also more effective under stimulatory than under inhibitory photoperiod (Lincoln et al., 1987). Moreover, opioidergic pathways do not seem to participate in the induction of puberty in either male or female sheep (Wood et al., 1992; McShane ef al., 1993), or even in the amenorrhoea associated with heavy exercise in humans (Jenkins and Grossman, 1993). It is becoming increasingly difficult to conceptualize a simple model in which opioidergic systems play a pivotal role in $\mathrm{GnRH}$ responses to environmental inputs. 
Other neural systems. Other neural systems that might play a part in the responses of the GnRH pulse generator have been discussed in some detail by I'Anson et al. (1991) and will be mentioned only briefly here. Cells containing neuropeptide $Y$ have been studied in relation to the control of puberty in female sheep. The inhibition of pulsatile LH secretion in underfed ewe lambs is inversely related to the concentrations of neuropeptide $Y$, and the RNA encoding it, in the median eminence and hypothalamus (Ober and Malven, 1992; McShane et al., 1993). These observations are consistent with the hypothesis that undernutrition increases the activity of neurones containing neuropeptide $Y$ and this leads to inhibition of gonadotrophin secretion. This concept has not yet been extended to mature ruminants, but it should generate interest because studies in rodents have shown that neurones containing neuropeptide $Y$ are intimately involved in the control of appetite (Morley, 1987) and appear to play a role in the photoperiodically driven changes in appetite (Boswell et al., 1993). In mature Cashmere bucks, the seasonal cycle in testicular size appears to be more closely linked to the seasonal cycle in appetite than to the annual (presumably photoperiodic) pattern of gonadotrophin secretion (Walkden-Brown et al., 1994c), suggesting a causal link between these phenomena that might be mediated by neuropeptide $Y$ systems.

Thus, the attraction of neuropeptide $Y$ hypotheses lies in the nutritional influences on reproductive activity being mediated entirely within the hypothalamus, through interactions between the appetite centres and the reproductive centres. Other attractive hypotheses are based on the 'gut' peptides, such as cholecystokinin, that are also involved in central appetite confrol (Morly, 1987) and have also been shown to stimulate the secretion of LH in primates (Perera et al., 1993; Schreihofer et al., 1993).

\section{Mechanisms independent of changes in GnRH secretion}

The acute effects of the lupin stimulus on gonadotrophin secretion in mature Merino sheep are very clear and highly repeatable. However, if we take a broader, longer-term view, there are too many inconsistencies in the data for all of the testicular responses to be attributed to changes in the activity of the GnRH-gonadotrophin system. First, in rams on a high plane of nutrition, the testes continued to grow for 2-3 months, despite the fact that gonadotrophin secretion had returned to normal (Martin et al., 1994a). Second, under-and over-nutrition consistently exerted opposite effects on testicular size, but not on gonadotrophin patterns (Alkass et al., 1982; Martin et al., 1994a). Third, in Cashmere bucks during the non-breeding season, increasing the plane of nutrition above maintenance led to rapid and persistent (4 months) testicular growth without any detectable effects on the secretion of gonadotrophins (Walkden-Brown et al., 1994c).

There is little doubt that the gonadotrophins are essential for testicular growth, development and function. However, the above observations led us to develop the concept that nutrition affects testicular growth, and therefore production of spermatozoa, by two mechanisms (i) the classical control pathway, involving changes in activity of the hypothalamic centres controlling GnRH pulse frequency, and thus changes in the secretion of gonadotrophins; this we have termed the GnRH-dependent pathway; and (ii) another pathway (or group of pathways) that promotes testicular growth in the absence of changes in GnRH pulse frequency or gonadotrophin secretion; we have termed this the GnRH-independent pathway (Martin et al, 1992, 1994b)

We have just begun to test this idea in detail and we have good evidence for GnRHindependent mechanisms based on the effects of nutrition on testicular size in rams immunized against GnRH (Hötzel et al., 1993) and our finding that nutrition influences testicular size, but not gonadotrophin concentrations, in rams on a fixed regimen of exogenous GnRH pulses (Hötzel et al., 1994).

The hormones of the somatotrophic axis (growth hormone and insulin-like growth factor 1 (IGF-I)) might act on the testes to mediate some of the effects of nutrition on the production of spermatozoa. Change in testicular mass is often closely associated with change in bodymass and the testes contain receptors for both IGF-I and growth hormone. Moreover, IGF-I is recognized as having a role in the regulation of spermatogenesis (Spiteri-Grech and Nieschlag, 1992), although the relative importance of circulating and locally produced, intratesticular IGF-I is not clear. We have recently tested the role of the somatotrophic axis in mediating the effects of nutrition on the testes by immunizing mature Merino rams against growth hormone-releasing hormone (GHRH) and 


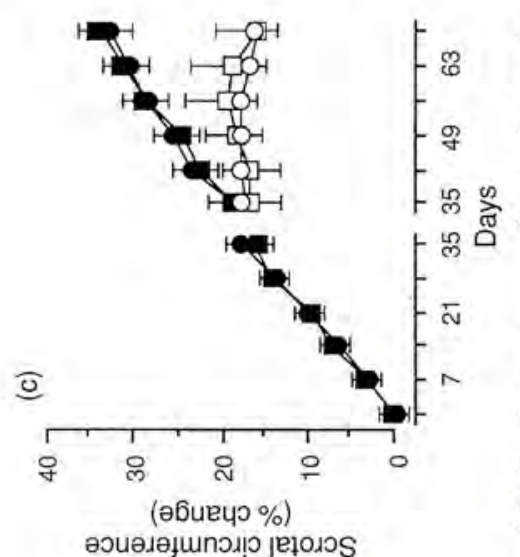

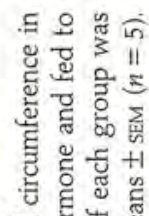

त्ञ 응 है

暨, 要

. 迎 㟧

品 즌

등 웡

당워

통요

(동 중

पह हू

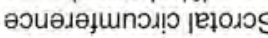

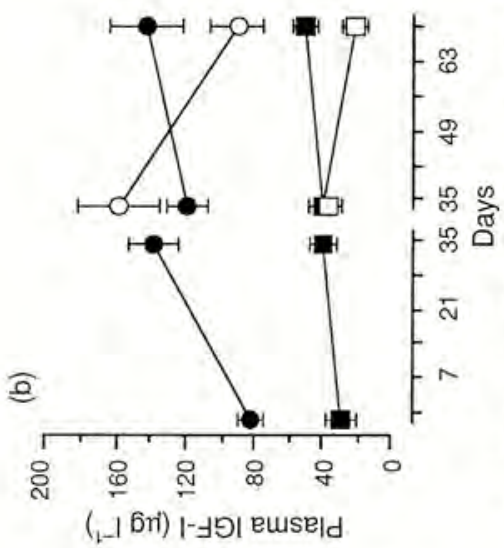

00

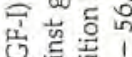

我新

홍 댕

矛 을

도 है

结足

के है

冚氜的

독동

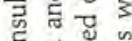

으음

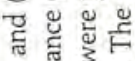

돌 है

돓 동

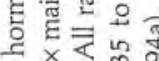

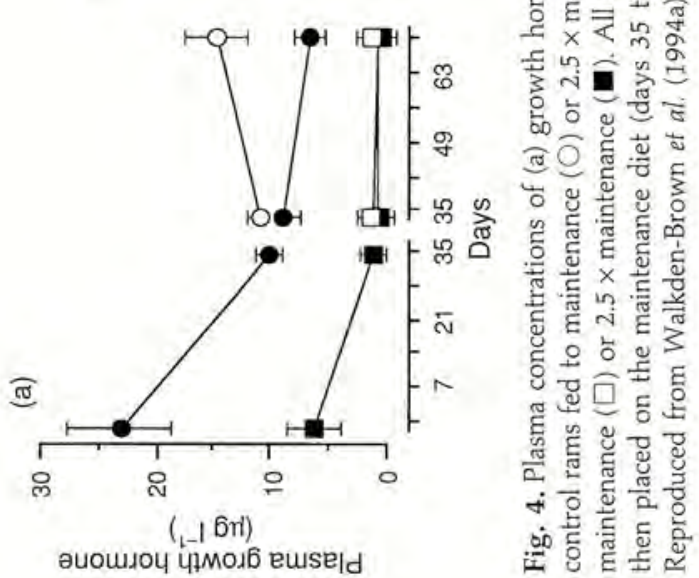


then offering them diets that provided $100 \%$ or $250 \%$ of their requirements for maintenance (Walkden-Brown et al., 1994a). Immunization reduced growth hormone and IGF-I concentrations to very low values, but the treatment had no effect on the testicular response to nutrition (Fig. 4). These findings clearly do not support a direct role for the somatotrophic axis in mediating the effects of nutrition on the testis of rams, but they do not preclude a role for intratesticular [GF-I, which is not under growth hormone control.

\section{Nutritional and Metabolic Signals}

The diets, including lupin grain, used to induce testicular growth in many studies, are high in both protein and energy, raising the question of which of these major dietary components is most important in regulating testicular function. This is an important issue because it provides the starting point for more detailed investigation of the physiological pathways involved. For example, if energy supply was found to be important, we would need to test whether the energy substrates themselves, or the metabolic control systems involved in energy homeostasis, act on the reproductive axis. If protein were important, we might be led to consider the influences of changes in the supply of those amino acids that act as substrates for the synthesis of neurotransmitters (Schillo, 1992; Jenkins and Grossman, 1993).

The early literature contains many references to the protein content of the diet, but few of them compared rigorously designed rations that were balanced in nitrogen and energy contents. Braden et al. (1974) clarified the situation with two experiments which clearly showed that the testicular response of Merino rams is related primarily to the energetic component of the diet rather than to the protein content. This conclusion was strongly supported by the detailed work of Murray et al. (1990). However, there is little doubt that an appropriate balance of protein and energy is required to maintain testicular function and that animals that are severely deficient in protein are unlikely to maintain testicular growth at the expense of other tissues.

\section{Interactions between the metabolic and reproductive control systems}

In further pursuing the role of energy in the responses of Merino rams to lupin grain, we tested whether the reproductive axis was influenced by the glucose-insulin system.

Glucose is the principal source of metabolic energy for the ram testis (Setchell and Hinks, 1967) and for the ruminant brain (Pell and Bergman, 1983). Insulin was implicated because, in rats, it can cross the blood-brain barrier into the cerebrospinal fluid (CSF), from where it is taken up by neural tissues (Baskin et al, 1987; Schwartz et al., 1990), presumably those that contain insulin receptors, such as the median eminence and mediobasal hypothalamus (Van Houten et al., 1980; Baskin et al., 1987). These areas are important in the control of GnRH release in sheep (Thiéry and Martin, 1991).

In rams, the lupin supplement increases insulin concentrations in peripheral plasma as well as cerebrospinal fluid, where the values are about 10\% of those in plasma (Miller et al., 1993; Martin et al., 1994b). In both plasma and cerebrospinal fluid, there is a tendency for glucose concentrations to increase too, but they generally differ little from control values, presumably because of the regulatory influence of the extra insulin. We tried to test the role of the glucose-insulin system by intravenous and intra-abomasal infusions of glucose. These treatments greatly increased the circulating concentrations of both glucose and insulin, but had no effect on gonadotrophin secretion or testicular growth (Boukhliq et al., 1991, 1992). We tested the intracerebral route for administration of insulin by injecting it into the third ventricle. In contrast to underfed ewe lambs (Schillo, 1992), this treatment increased LH pulse frequency in mature Merino rams on a maintenance diet (Miller et al, 1994); further work is therefore required before it is known whether insulin-glucose interactions can provide a nutritional signal that directly affects the reproductive axis.

It is important to remember that $70 \%$ of the energy requirement of ruminants is met by the volatile fatty acids, primarily acetate, propionate and butyrate, that are produced by fermentation in the rumen (Bergman, 1990). They are rapidly absorbed into the ruminal epithelium, where most of the butyrate is metabolized. Propionate is the only glucogenic volatile fatty acid and virtually all of it 
is absorbed immediately from the portal bloodstream by the liver where it is used for the production of glucose. Most of the acetate enters the general circulation and is used directly as an energy substrate by most peripheral tissues (Bergman, 1990). The possibility that volatile fatty acids could act as a nutritional signal was suggested by Murray et al. (1990), who observed a tendency for testicular growth to increase in rams fed a mixture of volatile fatty acids as a dietary supplement. This effect was subsequently confirmed by Boukhliq et al. (1992, 1993), who also found that this treatment increased LH pulse frequency and FSH concentrations, although it was not as effective as the lupin supplement.

We have not completely rejected a role for protein or amino acids. Up to $35 \%$ of the protein in lupin grain seems to escape fermentation and pass to the abomasum (Hume, 1974), where it is broken down and absorbed in much the same way as in monogastrics. However, intra-abomasal infusion of casein did not affect testicular growth in Merino rams, in the presence or absence of exogenous glucose (Boukhliq ef al., 1992), but it did increase FSH secretion (Martin ef al, 1992) and tended to increase LH pulse frequency. It is therefore possible to question whether a full response to protein requires a particular combination of amino acids, perhaps one that differs from casein.

It is clear that we have only just begun to unravel these mechanisms and that this area of investigation has a lot of potential, particularly as the volatile fatty acids, insulin and glucose all seem to be involved in appetite control and, as we have pointed out above, there are strong links between reproductive activity and appetite in seasonal breeders. The first step might be to determine which of the volatile fatty acids elicited the endocrine response. Another important consideration is that attention has been focused exclusively on gonadotrophin secretion as an endpoint. We have yet to address the $\mathrm{GnRH}$-independent pathways, which might respond differently to both energy and protein in the diet.

\section{Conclusions}

Understanding of the numerous ways in which nutrition influences the reproductive system is improving (Fig. 5). For mature male sheep, there is strong evidence for the GnRH-dependent pathways. Nutrient supply changes $\mathrm{GnRH}$ pulse frequency and thus LH and FSH secretion. This hypothalamic effect seems to involve changes in the responsiveness of the $\mathrm{GnRH}$ pulse generator to negative feedback through mechanisms that are independent of the opioidergic neurones. The nutritional factor exerting these effects still awaits identification. Candidates include the volatile fatty acids and intrahypothalamic insulin, both of which affect GnRH pulse frequency (Fig. 5). Changes in glucose supply do not seem to be involved.

For mature male sheep and goats, there is also strong evidence for the existence of GnRHindependent pathways (Fig. 5), but we have little idea of their composition. Nutrients might directly supply substrates for the seminiferous tubules or the interstitial cells, but the absolute requirement for protein or energy for production of hormones and germ cells is small and current indications are that the endocrine function of the testis of mature animals is poorly related to nutrition. More likely pathways involve effects of nutritional status on the patterns of secretion of the hormones that control the metabolic system (Fig. 5). Information on the effects of these hormones on gonadal tissues is scarce at present, but the field is developing rapidly, particularly in relation to ovarian function (Lindsay et al,, 1993). Our studies have led us to suggest that the somatotrophic axis does not play a direct role in rams, but intratesticular IGF-I still awaits investigation.

Liver mechanisms (Fig. 5) have not been described in this review because few data are available for male ruminants. However, they are potentially important (Lindsay et al. (1993) and have been included for the sake of completion. In rats, the activities of the various enzymes controlling steroid metabolism in the liver are under the control of growth hormone, so diet-induced changes in the secretion of growth hormone might alter the products of steroid metabolism. In addition, nutritional stress affects blood flow to the liver and may thus affect the rate of clearance of steroids and inhibin from the blood. Both pathways could affect the biological activity of the circulating steroids with respect to negative feedback, and thus the secretion of gonadotrophins. We do not know whether growth hormone affects steroid 


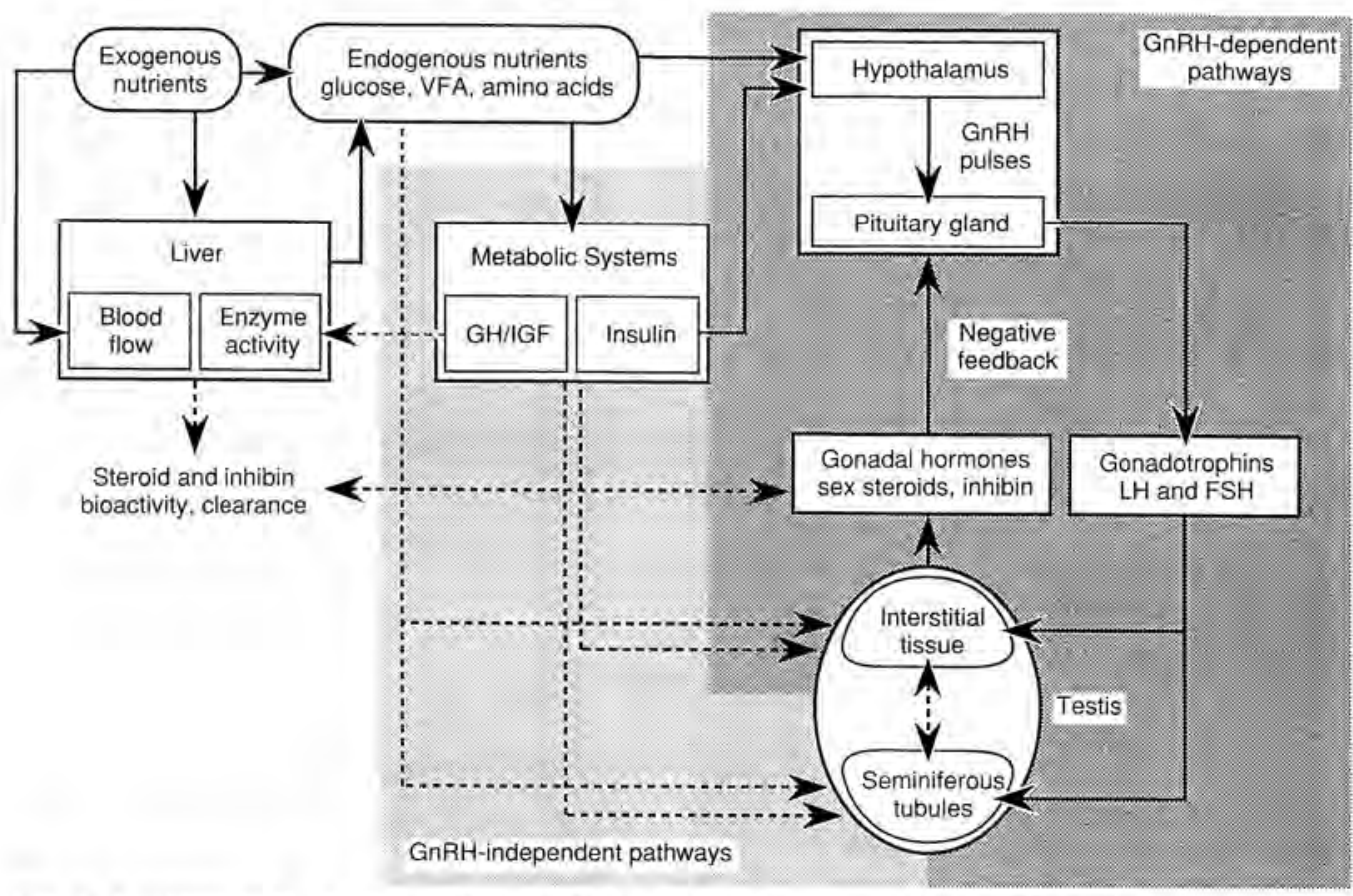

Fig. 5. A schema of the pathways through which nutritional stimuli might affect testicular activity. There is evidence to support some of these pathways in the mature male ruminant (solid lines). This is particularly so for the $\mathrm{GnRH}$-dependent pathways that involve changes in $\mathrm{GnRH}$ pulse frequency and thus gonadotrophin secretion. The actions of this pathway on seminiferous tubular activity have been clearly documented, but there appears to be little effect on the function of the interstitial tissue, particularly testosterone secretion. However, intratesticular testosterone is critical for the normal function of the seminiferous tissue, and the role of this relationship in the effects of nutrition on the production of spermatozoa has not been assessed. The pathways indicated by broken lines are hypothetical, being supported by circumstantial evidence in male sheep and goats, or by data from studies of female ruminants or monogastric species. There is good evidence to support the existence of GnRH-independent pathways but we have little idea of the systems that comprise them. The liver pathways basically lead to changes in the intensity of the negative feedback exerted by the gonadal steroids and inhibin on the hypothalamic-pituitary axis (Lindsay et al., 1993). These pathways remain to be tested in male ruminants.

metabolism in ruminants, but there is evidence that progesterone clearance is altered in ewes. For mature male ruminants, this area requires investigation.

The number and diversity of the interactions between the metabolic and reproductive systems contrasts with the mechanisms underlying responses to photoperiodic or socio-sexual cues, which are directed primarily through the final common pathway of the GnRH cells. This complexity has been a barrier to progress and probably explains many of the inconsistencies in the literature - it seems likely that males and females use different arrays of mechanisms, as do pubertal and mature animals of the same sex.

\section{References}

Alkass JE, Bryant JJ and Walton JS (1982) Some effects of level of feeding and body condition upon sperm production and gonadotropin concentrations in the ram Animal Production $34265-277$

Baskin DG, Figlewicz DP, Woods SC, Porte D Jr and Dorsa DM (1987) Insulin in the brain Amutal Review of Physiology 49 $335-347$
Bergman EN (1990) Energy contributions of volatile fatty acids from the gastrointestinal tract in various species Physiological Reviews $70507-590$

Boswell T, Richardson RD, Schwartz MW, D'Alessio DA, Woods SC, Sipols AJ, Baskin DG and Kenagy GJ (1993) NPY and galanin in a hibernator: hypothalamic gene expression and effects on feeding Brain Restarch Bullefin 32 379-384 
Boukhliq R, Martin GB and Adams NR (1991) Glucose infusion does not alter gonadotrophin levels in the ram Proceedings of the Australian Society for Reproductioe Biology 2339

Boukhliq R, Martin GB and Murray PJ (1992) Roles of energy and protein in the control of testicular growth in the ram Proceedings of the Australian Society for Reproductive Biology 24100

Boukhliq R, Miller DW and Martin GB (1993) Dietary fatty acids stimulate gonadotrophin secretion in the ram Proceedings of the Australian Saciety for Reproductive Biology 259

Braden AWH, Turnbull KE, Mattner PE and Moule GR (I974) Effect of protein and energy content of the diet on the rate of sperm production in rams Australian Jounal of Biological Sciences 27 67-73

Bronson FH and Manning JM (1991) The energetic regulation of ovulation: a realistic role for body fat Biology of Reproduction 44 945-950

Cameron AWN, Murphy PM and Oldham CM (1988) Nutrition of rams and output of spermatozoa Proceedings of the Anstralian Society of Animal Production 17 162-165

Clark RT (1934) Studies of reproduction in sheep. 1 . The ovulation rate of the ewe as affected by the plane of nutrition Anatomical Recond 60 125-134

Foster DL. (1994) Puberty in the female sheep. In The Phisiology of Reproduction (2nd Edr) Vol. 2 pp 411-452 Eds E Knobil and ID Neill. Raven Press, New York

Frisch RE (1974) The physiological basis of reproductive efficiency. In Meat Animals Growth and Productivity pp 327-354 Eds D Lister, DN Rhodes, VR Fowler and MF Fuller. Plenum Press, New York

Hiroe $\mathrm{K}$ and Tomizuka $\mathrm{T}$ (1965) Effects of nutrition on the characteristics of goat semen Bulfein of the National histitute of Animal Industrics \& 17-24

Hochereau-de Reviers MT, Perreau C and Lincoln GA (1985) Photoperiodic variations of somatic and germ cell populations in the Soay ram testis Journal of Reproduction and Ferfility 74, 329-334

Hötzel MJ. Martin GB and Markey CM (1993) Effect of nutrition on testicular function of rams immunised against GnRH Proceedings of the Endocrine Society of Australia 36102.

Hötzel MJ. Walkden-Brown, SW and Martin GB (1994) The effect of nutrition on testicular growth in mature Merino rams involves mechanisms that are independent of changes in GnRH pulse frequency Proceedings of the Endocrine Society of Australia 37 I33

Hume ID (1974) The proportion of dietary protein escaping degradation in the rumen of sheep fed on various protein concentrates Australian lournal of Agricultural Research 25 $155-165$

I'Anson H, Foster DL, Foxcroft GR and Booth PJ (1991) Nutrition and reproduction Oxford Reviews in Reproductive Biology 13 239-311

Jenkins PJ and Grossman A (1993) The control of the gonadotrophin releasing bormone pulse generator in relation to opiojd and nutritional cues Human Repmodiction $\mathbf{8}$ (Supplement 2) 154-16́ I

Lincoln GA and Short RV (1980) Seasonal breeding: nature's contraceptive Recent Progress in Hormone Rescarch 36 $1-52$

Lincoln GA, Ebling FJP and Martin GB (1987). Endogenous opioid control of pulsatile LH secretion in rams: modulation by photoperiod and gonadal steroids Joumal of Endocrinology $115 \quad 425-4.38$
Lindsay DR, Martin GB and Williams IH (1993) Nutrition and reproduction. In Reproduction in Domesticated AnimalsWorld Animal Science Series pp 459-49I Ed. GJ King. Elsevier Science Publishers, Amsterdam

McShane TM, Petersen SL, McCrone S and Keisler DH (1993) Influence of food restriction on neuropeptide-Y. proopiomelanocortin, and luteinizing hormone-releasing hormone gene expression in sheep hypothalami Biology of Reproduction $49831-839$

Martin GB, Sutherland SRD and Lindsay DR (1987) Effects of nutritional supplements on testicular size and the secretion of $\mathrm{LH}$ and testosterone in Merino and Booroola rams Animal Reproduction Science 12 267-28I

Martin GB, Boukhliq R, Tjondronegoro S, Hötzel M] and Fisher IS (1992) The effects of nutrition on reproductive endocrinology Proceedings of the Nutrition Society of Australia 17 177-185.

Martin GB, Tjondronegoro S and Blackberry MA (1994a) Effects of nutrition on testicular size and the concentrations of gonadotrophins, testosterone and inhibin in plasma of mature male sheep Journal of Reproutuction and Fertility 101 121-128

Martin GB, Walkden-Brown SW, Boukhliq R. Tjondronegoro S. Miller DW, Fisher JS, Hötzel MJ, Restall BJ and Adams NR (1994b) Non-photoperiodic inputs into seasonal breeding in male ruminants. In Perspectives in Comparative Endocrinol. ogy pp 574-585 Eds KG Davey, RE Peter and SS Tobe. National Research Council of Canada, Ottawa

Miller DW, Lane RIF, Boukhliq R, Hötzel MJ and Martin GB (1992) Nutrition and the opioidergic control of LH secretion in the ram Proceedings of the Endocrine Society of Australin 3559

Miller DW, Boukhliq R, Butt S and Martin GB (1993) Central nervous system concentrations of glucose and insulin during the nutritional stimulation of $\mathrm{LH}$ and $\mathrm{FSH}$ secretion in the ram Procedings of the Endocrine Society of Australia 36 71

Miller DW. Blache D. Boukhliq R and Martin GB (1994) Intracerebroventricular infusion of insulin stimulates $\mathrm{LH}$ in male sheep Procedings of the Endocrine Society of Australia 37125

Mori A (1959) Studies on the reproductive failure of ram caused by underfeeding. I. On the effects of underfeeding upon the mating potency of ram, and the effects of normal feeding upon its recovery from impotence Tolukh Jourial of Agricultural Research 10 263-281

Morley JE (1987) Neuropeptide regulation of appetite and weight Endocrine Revietws 8 256-287

Moule GR (1963) Postpubertal nutrition and reproduction by the male Australian Veterinary Joumal 39 299-304

Murray PI., Rowe IB, Pethick DW and Adams NR (1990) The effect of nutrition on testicular growth in the Merino ram Australian Journal of Agricultural Research 41 185-195

Ober JA and Malven PV (1992) Effect of growth retardation on pituitary luteinizing hormone and hypothalamic neuropeptide $Y$ in ovariectomized sheep Nouroendocrmology 56 33i-339

Oldham CM, Adams NR, Gherardi PB, Lindsay DR and Mackintosh JB (1978) The influence of level of feed intake on sperm producing capacity of testicular tissue in the ram Australian Jounal of Agricultural Research 29 173-179

Parr RA and Tilbrook AJ (1990) The influence of nutrition on circulating levels of testosterone in rams and testosteronetreated wethers Proceedings of the Australian Society of Animal Production 18 328-331 
Pell JM and Bergman EN (1983) Cerebral metabolism of amino acid and glucose in fed and fasted sheep American Journal of Physiology (Endocrinology and Metabolism) $\mathbf{2 4 4}$ E282-E289

Perera AD, Verbalis JG, Mikuma N, Majumdar SS and Plant TM (1993) Cholecystokinin stimulates gonadotropin-releasing hormone release in the monkey (Macaca mulatta) Endocrinology 132 1723-1728

Restall BJ (1992) Seasonal variation in reproductive activity in Australian goats Animal Reproduction Science 27 305-318

Ritar AJ, Adams NR and Sanders MR (1984) Effect of lupin feeding on LH, testosterone and testes. In Reproduction in Sheep pp 76-78 Eds DR Lindsay and DT Pearce. Cambridge University Press, Cambridge

Salamon S (1964) The effect of nutritional regimen on the potential semen production of rams Australian Joumal of Agricultural Research 15 645-656

Schanbacher BD (1985) Endogenous opiates and the hypothalamic-pituitary-gonadal axis in male sheep Domestic Animal Endocrinology 2 67-75

Schillo KK (1992) Effects of dietary energy on control of luteinizing hormone secretion in cattle and sheep Journal of Animal Science 70 1271-1282

Schreihofer DA, Golden GA and Cameron JL (1993) Cholecystokinin (CCK)-induced stimulation of luteinizing hormone (LH) secretion in adult male rhesus monkeys: examination of the role of CCK in nutritional regulation of LH secretion Endocrinology 132 1553-1560

Schwartz MW, Sipols A, Kahn SE, Lattemann DF, Taborsky GJ Jr, Bergman RN, Woods SC and Porte D Jr (1990) Kinetics and specificity of insulin uptake from plasma into cerebrospinal fluid American Journal of Physiology (Endocrinology and Metabolism) 259 E378-E383

Setchell BP and Hinks NT (1967) The importance of glucose in the oxidative metabolism of the testis of the conscious ram and the role of the pentose cycle Biochemical Journal 102 $623-630$
Setchell B, Waites GMH and Lindner HR (1965) Effect of undernutrition on testicular blood flow and metabolism and the output of testosterone in the ram Joumal of Reproduction and Fertility 9 149-162.

Spiteri-Grech J and Nieschlag E (1992) The role of growth hormone and insulin-like growth factor I in the regulation of male reproductive function Hormone Research 38 (Supplement 1) 22-27

Thiéry J-C and Martin GB (1991) Neurophysiological control of the secretion of gonadotrophin-releasing hormone and luteinising hormone in the sheep-a review Reproduction, Fertility and Development 3 137-173

Tilton WA, Warnick AC, Cunha TJ, Loggins PE and Shirley RL (1964) Effect of low energy and protein intake on growth and reproductive performance of young rams Joumal of Animal Science 23 645-650

Van Houten M, Posner BI, Kopriwa BM and Brawer JR (1980) Insulin binding sites localized to nerve terminals in rat median eminence and arcuate nucleus Science 207 1081-1083

Walkden-Brown SW, Hötzel MJ, Rigby RDG and Martin GB (1994a) Immunisation against growth hormone-releasing factor (GRF) does not affect the testicular response to nutrition in rams Proceedings of the Australian Society for Reproductive Biology 2676

Walkden-Brown SW, Restall BJ and Scaramuzzi RJ (1994b) Reproductive seasonality in male Australian cashmere goats Proceedings of the Australian Society of Animal Production 20366

Walkden-Brown SW, Restall BJ, Norton BW, Scaramuzzi RJ and Martin GB (1994c) Effect of nutrition on seasonal patterns of $\mathrm{LH}, \mathrm{FSH}$ and testosterone concentration, testicular mass, sebaceous gland volume and odour in Australian cashmere goats Journal of Reproduction and Fertility 102 351-360

Wood RI, I'Anson H, Ebling FJP and Foster DL (1992) Opioid inhibition of luteinizing hormone secretion compared in developing male and female sheep Neuroendocrinology 56 $822-830$ 